RAD Conference Proceedings, vol. 4, pp. 76-80, 2020

ISSN 2466-4626 (online) | DOI: 10.21175/RadProc.2020.16

www.rad-proceedings.org

\title{
INTRADUCTAL PAPILLARY MUCINOUS NEOPLASMS: RADIOLOGY METHODS IN THE DEFINITION OF TREATMENT TACTICS
}

\author{
Yulia A. Stepanova* \\ A.V. Vishnevsky National Medical Research Center of Surgery, Moscow, Russian Federation
}

\begin{abstract}
IPMN is a borderline malignant epithelial tumor that develops in the pancreatic duct and/or its lateral branches from mucin-producing cells. The aim is to evaluate the capabilities of radiology diagnostic methods in assessing IPMN, based on the analysis of literature data and personal experience. From 2004 to 2019, at A.V. Vishnevsky National Medical Research Center of Surgery (A.V. Vishnevsky NMRC of Surgery), 96 patients were examined and treated with morphologically verified IPMN, aged from 38 to 8o, with a somewhat larger share of men (57.3\%). Patients were subjected to the complete radiology examination: ultrasound (in B-mode and duplex scanning, with $3 D$ reconstruction, if it's necessary), multislice computed tomography (MSCT) and magnetic resonance imaging (MRI) with contrast enhancement. The following types of IPMN have been diagnosed: MD-IPMN - 19 cases (19.8\%), $B D-I P M N-46$ cases (47.9\%), combined-IPMN - 31 cases (32.3\%). The criteria of radiology diagnostics of the IPMN are as follows: extended duct throughout its range; thickening of its walls; parietal papillary proliferations of varying degrees of severity; possible single expanded segmental ducts and tumor masses around the main pancreatic duct. The MRCP is the priority method of diagnostics. In accordance with the criteria of tumor malignancy, 56 (58.3\%) patients were operated on, 40 (41.7\%) were under observation: Type 1: operated on - 17 (89.5\%); are under observation - 2 (10.5\%); Type 2: operated on - 12 (26.1\%); are under observation - 34 (73.9\%); Type 3: operated on 27 (87.1\%); are under observation - 4 (12.9\%). Thus, dynamic monitoring is carried out mainly for type II tumors. Despite the increase in the availability of radiological methods of examination, the diagnosis of IPMN can be difficult. Current guidelines provide indications for surgery and recommendations for surveillance, but management of IPMN is still challenging in routine clinical practice. Due to the high risk of tumor malignancy in types 1 and 3, timely correct diagnosis and determination of further treatment tactics are extremely important. MRI is a priority method for the diagnosis of IPMN, however, in some cases, the involvement of at least two methods of radiology diagnostics allows to establish the nature of the disease and determine the tactics of treatment.
\end{abstract}

Key words: Intraductal papillary mucinous neoplasms, diagnostic, US, MSCT, MRI, treatment tactics

\section{INTRODUCTION}

Due to development and promotion of new methods for abdominal diagnostic imaging, different specialists meet cystic lesions of the pancreas more often. By late 1970s, the range of known cystic pancreatic neoplasms was represented mainly by serous and mucinous tumors. In the 80 s and 9os, due to the rapid development of diagnostic and surgical techniques, it has considerably grown. In the past 20 years, it has been reported on previously undifferentiated diseases of the pancreas, i.e. intraductal papillary mucinous neoplasms (IPMN), solid pseudopapillary tumors, cystic form of duodenal dystrophy and others.

IPMN is a borderline malignant epithelial tumor that develops in the pancreatic duct and/or its lateral branches from mucin-producing cells [1]. It is characterized by the secretion of large amounts of extracellular mucus, the papillary type of growth, accumulation of mucus in the pancreatic ducts, a high degree of resectability and good prognosis [2]. The incidence of IPMN is higher in men and ranges from
0.31 to 4.35 cases per 100,000 people]. The average age of patients at the time of diagnosis is 64 years [3].

Depending on the localization in the pancreatic ducts, there are three types of IPMN: type 1 - damage to the main pancreatic duct (MD) along its entire length or segmental; type 2 - damage to the lateral branches of the pancreas duct (BD); type 3 is a combination of the first two [4]. In the pancreas, several independent IPMN s (multicentric growth) may occur [5].

The first report on IPMN was made more than 70 years ago, but the characteristic features of these neoplasms were not taken into account until $\mathrm{K}$. Ohhashi et al. reported in 1982 on a series of cases of mucin-producing pancreatic tumors. They diagnosed a malignant tumor of the pancreas, which was accompanied by a significant expansion of the main pancreatic duct, the accumulation of a large amount of mucin in its lumen and a gaping of the mouth of the large duodenal papilla - the Ohhashi triad [6]. This condition has been termed "mucus-producing pancreatic cancer." It was noticed that a similar variant of a tumor lesion of the pancreas is accompanied by high resectability and a rather favorable prognosis for

* stepanovaua@mail.ru 
Y. A. Stepanova, Intraductal papillary mucinous neoplasms..., RAD Conf. Proc., vol. 4, 2020, 76-80

the patient's life. Later it became known that the described changes can occur not only in malignant tumors, but also in borderline, as well as in benign neoplasms of the pancreas [7].

Diagnosis of IPMN is complicated by objective reasons, which are the scarcity of clinical manifestations, the variety of radiology manifestations. Despite the recent increase in the number of publications devoted to IPMN, the awareness and skills of interpreting radiology images among doctors are insufficient. When confronted with such patients, gastroenterologists and general surgeons often misinterpret IPMN as chronic pancreatitis, resulting in delayed treatment. It should also be noted that as experience in diagnostics, treatment and histopathological study of IPMN was gained, the attitude towards the tactics of managing such patients changed in the direction of a more restrained attitude towards the indications for surgery, depending on the type of tumor.

\section{AIM}

The aim of the study is to evaluate the capabilities of radiology diagnostic methods in assessing IPMN, based on the analysis of literature data and personal experience.

\section{MATERIALS AND METHODS}

From 2004 to 2019, at A.V. Vishnevsky National Medical Research Center of Surgery (A.V. Vishnevsky NMRC of Surgery), 96 patients were examined and treated with morphologically verified IPMN, aged from 38 to 80 , with a somewhat larger share of men (57.3\%). Patients were subjected to the complete radiology examination: ultrasound (in B-mode and duplex scanning, with $3 \mathrm{D}$ reconstruction, if it's necessary), multislice computed tomography (MSCT) and magnetic resonance imaging (MRI) with contrast enhancement.

\section{RESULTS AND DISCUSSION}

Complaints were presented by $80.2 \%$ of patients. This does not coincide with the literature data [2], however, it is explained by the fact that A.V. Vishnevsky NMRC of Surgery is a planned surgical clinic that does not conduct a mass screening examination. The absence of complaints was due to the localization of IPMN in the distal part of the pancreas or a relatively low degree of mucin production. Complaints of discomfort and / or epigastric pain, irradiation of back pain and weight loss were reported by $89.6 \%$ of patients. In $6.5 \%$ of cases, the clinical picture of moderate acute pancreatitis prevailed. Obstructive jaundice of varying severity was diagnosed in $44.2 \%$ of cases. In all of these cases, the tumor was localized in the head of the pancreas. Obstructive jaundice was caused either as a result of clogging of the ampulla of Vater's nipple with viscous mucus, or when the common bile duct was compressed by a massive, usually malignant tumor, or when a solid component of the tumor had grown into the wall of the common bile duct.

The following types of IPMN have been diagnosed: MD-IPMN - 19 cases (19.8\%), BD-IPMN - 46 cases (47.9\%), combined-IPMN - 31 cases (32.3\%).

At US IPMN is featured by an extended MD with possible segmental duct extension, walls thickening, parietal papillary excrescencies with varying degrees of severity, possible tumor mass lesion around the MD, as well as an absence of blood flow in the structure of the tumor masses at duplex scanning.

At MSCT, IPMN appears as an extended MD with thickened walls, parietal soft tissue growth with density of up to $43 \mathrm{HU}$, soft tissue lesion around the MD, accumulating contrast agent through all phases of the examination.

MRI shows the MD extension with wall thickening, as well as thickened segmental ducts of the first order (especially at the magnetic resonance cholangiopancreatography (MRCP), parietal soft tissue growth, soft tissue lesion around the MD, accumulating contrast agent through all phases of the examination.

MD-IPMN. All radiology methods (US, MSCT, and MRI) allow defining diagnosis independently (Fig. 1).
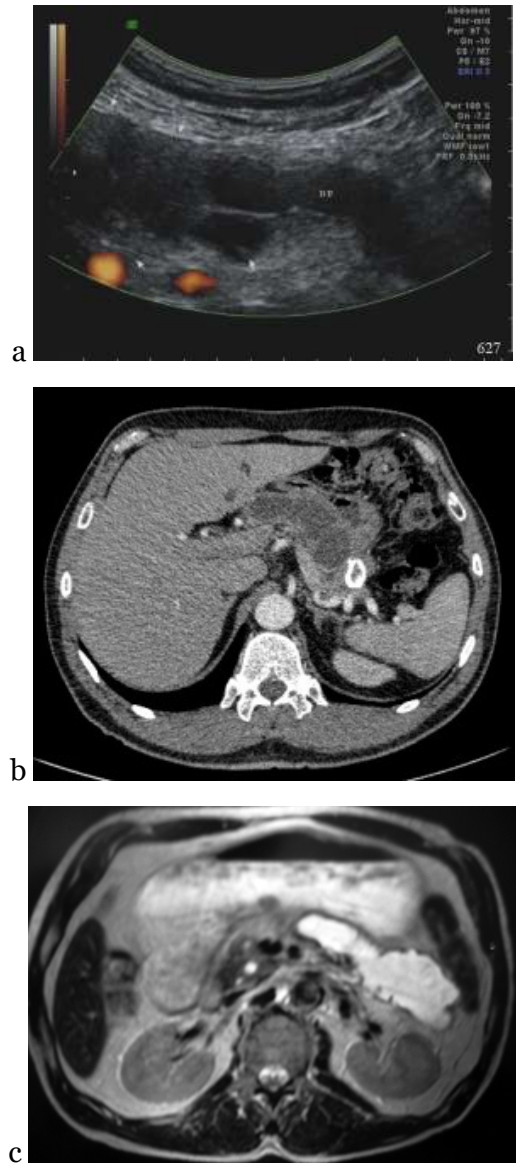

Figure 1. MD-IPMN: a - US image (DP - main pancreatic duct, arrows indicated papillary proliferations and extended parietal branch duct of the second order); $b$ - MSCT image; $\mathrm{c}-\mathrm{MR}$ image 
BD-IPMN. At US and MSCT, the branch ducts are poorly available to visualization due to their insignificant diameter in unaffected parts, that is why the connection of individual small cystic cavities in the pancreatic parenchyma with the main duct is not always possible to determine. MRCP becomes the method of choice (Fig. 2), making it possible to clearly differentiate cystic cavities associated with the main pancreatic duct.
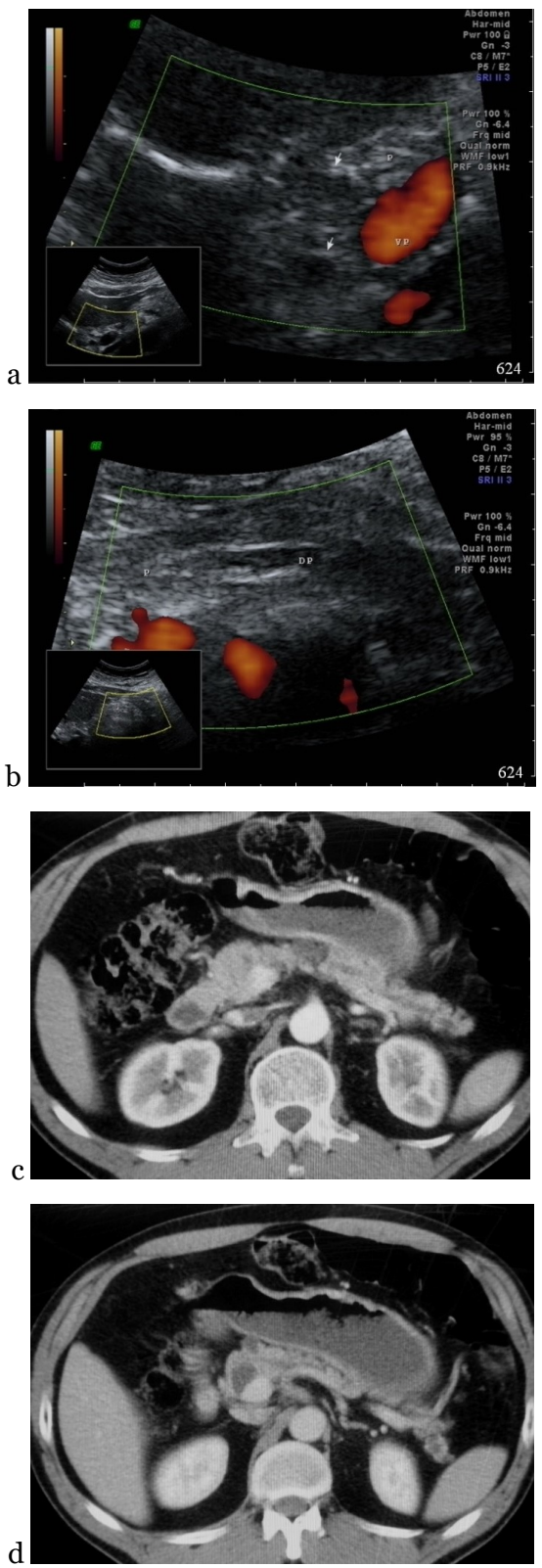

Figure 2. BD-IPMN: a, b - US images (VP - vena portae, $\mathrm{P}$ - pancreas, DP - main pancreatic duct, arrows indicated separate small cystic cavities of branch ducts); b - MSCT image; e - MRCP image

Combined-IPMN (Fig. 3). Our experience in diagnostics, treatment and morphological studies of this type of neoplasms suggests that, most likely, this type of IPMN is a progression of either MD-IPMN or BD-IPMN. Despite the fact that all methods of radiology diagnostics allowed to get the diagnostic in lesion at the combined-IPMN, as is the case of MDIPMN and BD-IPMN, the greatest diagnostic capacity belongs to MRCP, as it allows tracking of both MD and BD-IPMN in three dimensions throughout its extension.
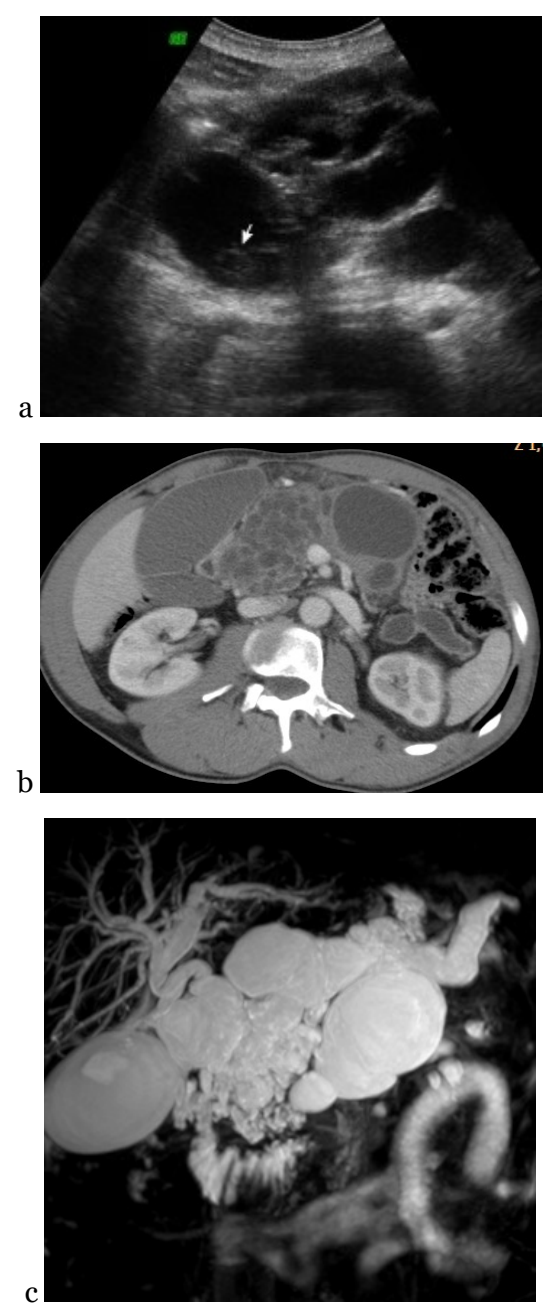

Figure 3. Combined-IPMN: a - US image (arrow indicated papillary proliferations); $\mathrm{b}-$ MSCT image; $\mathrm{c}-\mathrm{MRCP}$ image

Thus, the criteria of radiology diagnostics of the IPMN are as follows: extended duct throughout its range; thickening of its walls; parietal papillary proliferations of varying degrees of severity; possible single expanded segmental ducts and tumor masses around the main pancreatic duct. The MRCP is the priority method of diagnostics.

Tumor malignancy criteria [8]: obstructive jaundice; parietal papillary growths of more than $5 \mathrm{~mm} /$ presence of a solid component; the presence of tumor cells during cytological examination; the diameter of the pancreatic duct is more than $10 \mathrm{~mm}$. 
Y. A. Stepanova, Intraductal papillary mucinous neoplasms..., RAD Conf. Proc., vol. 4, 2020, 76-80

In accordance with these criteria, 56 (58.3\%) patients were operated on, 40 (41.7\%) were under observation:

Type 1: operated on - 17 (89.5\%); are under observation - 2 (10.5\%);

Type 2: operated on - 12 (26.1\%); are under observation - 34 (73.9\%);

Type 3: operated on - 27 (87.1\%); are under observation - 4 (12.9\%).

Thus, dynamic monitoring is carried out mainly for type II tumors. In only 2 cases, dynamic monitoring for tumors of this type required surgery.

The observation is carried out according to the following scheme: after 3 months, after 3 months, then 1 time in 6 months. The scope of the examination during the follow-up: MSCT and / or MRI and the tumor marker CA 19-9.

Criteria for malignancy in dynamic observation: newly detected expansion of the pancreatic duct 5-10 $\mathrm{mm}$; an increase in the cystic component over $5 \mathrm{~mm}$ in 1 year; newly identified parietal papillary growths up to $5 \mathrm{~mm}$; the appearance of a solid component; transition to type III; an increase in CA 19-9 [8].

The number of patients with IPMN has increased significantly over the past decade due to the rapid development of radiology diagnostics and their widespread use in outpatient settings [9]. The risk of tumor malignancy is different. The probability of malignant transformation is higher in the case of types 1 and 3 of the tumor and is 48 and $42 \%$, respectively [10]. In the presence of several type 1 IPMNs, the risk of developing carcinoma increases to 90\% [11]. For IPMN type 2, malignancy is $11 \%$ [10]. Thus, radiology methods of examination are currently at the forefront in determining the tactics of managing patients with IPMN, both during the initial detection and during dynamic monitoring.

Currently, cross-sectional imaging plays a main role in lesion detection and differentiation. MRI (combined with MRCP) is the modality of choice, because of its superiority in cyst differentiation and identification of MPD connectivity, mural nodules, and septation, as well as cyst differentiation. Additionally, the repetitive nature of cyst follow-up mandates a non-invasive modality to eliminate radiation exposure. However, for identification of calcifications, tumour staging or surveillance of PDAC recurrence, addition of CT is recommended by some [8], [12], [13].

\section{CONCLUSION}

Despite the increase in the availability of radiological methods of examination, the diagnosis of IPMN can be difficult. Current guidelines provide indications for surgery and recommendations for surveillance, but management of IPMN is still challenging in routine clinical practice. Due to the high risk of tumor malignancy in types 1 and 3 , timely correct diagnosis and determination of further treatment tactics are extremely important. MRI is a priority method for the diagnosis of IPMN, however, in some cases, the involvement of at least two methods of radiology diagnostics allows to establish the nature of the disease and determine the tactics of treatment.

\section{REFERENCES}

1. I.D. Nagtegaal, R.D. Odze, D. Klimstra, V. Paradis, M. Rugge, P. Schirmacher, K.M. Washington, F. Carneiro, I.A. Cree, "WHO Classification of Tumours Editorial Board. The 2019 WHO classification of tumours of the digestive system," Histopathology, vol. 76, no. 2, pp. 182-188, 2020. http://dx.doi.org/10.1111/his.13975.

2. Ю.А. Степанова, “Лучевые методы диагностики кистозных образований поджелудочной железы и парапанкреатической зоны на этапах хирургического лечения,” Дисс. ... докт. мед. наук. Москва, 2009; 398 с. (Yu.A. Stepanova, "Radiology methods of diagnostics of cystic lesions of the pancreas and parapancreatic zone at the stages of surgical treatment," Ph.D. dissertation, Moscow, Russia, 398 pages, 2009).

Retrieved from:

http://medical-diss.com/medicina/luchevye-metodydiagnostiki-kistoznyh-obrazovaniy-podzheludochnoyzhelezy-i-parapankreaticheskoy-zony-na-etapahhirurgich

Retrieved on: Sep. 27, 2020

3. E. Buscarini et al., "Italian consensus guidelines for the diagnostic work-up and follow-up of cystic pancreatic neoplasms," Dig. Liver Dis., vol. 46, no. 6, pp. 479-493, 2014.

http://dx.doi.org/10.1016/j.dld.2013.12.019

4. J.H. Lim, G. Lee, Y.L. Oh, "Radiologic Spectrum of Intraductal Papillary Mucinous Tumor of the Pancreas," RadioGraphics, vol. 21, pp. 323-340, 2001. http://dx.doi.org/10.1148/radiographics.21.2.go1mro13 23

5. Y. Mori, T. Ohtsuka, H. Kono, N. Ideno, T. Aso, Y. Nagayoshi, S. Takahata, M. Nakamura, K. Ishigami, S. Aishima, Y. Oda, M. Tanaka, "Management strategy for multifocal branch duct intraductal papillary mucinous neoplasms of the pancreas," Pancreas, vol. 41, no. 7, pp. 1008-1012, 2012. http://dx.doi.org/10.1097/MPA.ob013e31824b22c6.

6. K. Ohhashi, F. Murakami, M. Maruyama, T. Takekoshi, H. Ohta, I. Ohhashi, K. Takagi, Y. Kato, "Four cases of mucous secreting pancreatic cancer," Prog. Digest Endosc., vol. 20, pp. 348-351, 1982.

7. Ю.А. Степанова, Г.Г. Кармазановский, В.И. Егоров, А.В. Кочатков, Е.А. Дубова, И.А. Косова, Е.Н. Солодинина, “Лучевые методы Лучевые методы диагностики диагностики внутрипротоковых папиллярных внутрипротоковых папиллярных муцинозных опухолей,” Анналы хирургической гепатологии, т. 14, no. 3, стр. 69-79, 2009. (Yu.A. Stepanova, G.G. Karmazanovsky, V.I. Egorov, A.V. Kochatkov, E.A. Dubova, I.A. Kosova, E.N. Solodinina, "Radiaology methods of the diagnosis of intraductal papillary mucinous neoplasms," Annals of Surgical Hepatology, vol. 14, no. 3, pp. 69-79, 2009 (In Rus.)

8. The European Study Group on Cystic Tumours of the Pancreas, "European evidence-based guidelines on pancreatic cystic neoplasms," Gut, vol. 67, pp. 789-804, 2018. http://dx.doi.org/10.1136/gutjnl-2018-316027

9. M. Moris, M.D. Bridges, R.A. Pooley, M. Raimondo, T.A. Woodward, J.A. Stauffer, H.J. Asbun, M.B. Wallace, "Association Between Advances in HighResolution Cross-Section Imaging Technologies and Increase in Prevalence of Pancreatic Cysts From 2005 
Y. A. Stepanova, Intraductal papillary mucinous neoplasms..., RAD Conf. Proc., vol. 4, 2020, 76-80

to 2014," Clin. Gastroenterol. Hepatol, vol. 14, pp. 585-593, 2016/

http://dx.doi.org/10.1016/i.cgh.2015.08.038.

10. S. Crippa, C. Fernández-Del Castillo, R. Salvia, D. Finkelstein, C. Bassi, I. Domínguez, A. Muzikansky, S.P. Thayer, M. Falconi, M. Mino-Kenudson, P. Capelli, G.Y. Lauwers, S. Partelli, P. Pederzoli, A.L. Warshaw, "Mucin-producing neoplasms of the pancreas: an analysis of distinguishing clinical and epidemiologic characteristics," Clin Gastroenterol Hepatol, vol. 8, no. 2, pp. 213-219, 2010 Feb. http://dx.doi.org/10.1016/j.cgh.2009.10.001

11. L. Aronsson, R. Andersson, D. Ansari, "Intraductal papillary mucinous neoplasm of the pancreas epidemiology, risk factors, diagnosis, and management," Scand. J. Gastroenterol., vol. 52, no. 8, pp. 803-815, 2017 Aug.

http://dx.doi.org/10.1080/00365521.2017.1318948
12. S.J. Song, J.M. Lee, Y.J. Kim, S.H. Kim, J.Y. Lee, J.K. Han, B.I. Choi, "Differentiation of intraductal papillary mucinous neoplasms from other pancreatic cystic masses: comparison of multirow-detector CT and MR imaging using ROC analysis," J. Magn. Reson. Imaging, vol. 26, no. 1, pp. 86-93, 2007. http://dx.doi.org/10.1002/jmri.21001

13. M. Tanaka, C. Fernández-Del Castillo, T. Kamisawa, J.Y. Jang, P. Levy, T. Ohtsuka, R. Salvia, Y. Shimizu, M. Tada, C.L. Wolfgang, "Revisions of international consensus Fukuoka guidelines for the management of IPMN of the pancreas," Pancreatology, vol. 17, no. 5, pp. 738-753, 2017.

http://dx.doi.org/10.1016/j.pan.2017.07.007 